Check for updates

Cite this: RSC Adv., 2018, 8, 41280

Received 9th September 2018

DOI: $10.1039 / c 8 r a 07509 c$

rsc.li/rsc-advances
Accepted 1st December 2018

\section{The effects of amino substituents on the enhanced ammonia sensing performance of $\mathrm{PcCo} / \mathrm{rGO}$ hybrids $\uparrow$} \author{
and Yiqun $\mathrm{Wu}^{\text {ad }}$
}

Bin Wang, (D) *a Xiaolin Wang, ${ }^{* b}$ Xiaocheng Li, ${ }^{a}$ Zhijiang Guo, ${ }^{a}$ Xin Zhou ${ }^{c}$

Three reversible ammonia $\left(\mathrm{NH}_{3}\right)$ gas sensors were fabricated using tetra- $\alpha$-( $p$-aminobenzyloxy) phthalocyanine cobalt (ABOPCCO), tetra- $\alpha$-aminophthalocyanine cobalt (APcCo) and substituent-free phthalocyanine cobalt ( $F P C C O$ ) functionalized reduced graphene oxide ( $\mathrm{FO}$ ), with cost-efficient, highly sensitive and stable sensing performance. These hybrid materials were prepared via a facile physical solution mixing self-assembly reaction with $\mathrm{rGO}$ and PcCo solutions. The obtained PcCo/rGO hybrid sensors exhibit excellent sensing performance; especially the ABOPcCo/rGO sensor, whose response is about 23.3\% (50 ppm), with a limit of detection as low as 78 ppb, and response and recovery times about as fast as $225 \mathrm{~s}$ and $250 \mathrm{~s}$. The performance of the PcCo/rGO hybrid sensors can be optimized by adjusting the concentrations of the PcCo/rGO aqueous dispersions. More importantly, the $\mathrm{NH}_{3}$-sensing performance of the PcCo/rGO sensors was tuned by adjusting the substituent structure of PcCo. The enhanced $\mathrm{NH}_{3}$-sensing performance may be attributed to synergistic effects between PcCo and $\mathrm{rGO}$, e.g., stronger adsorption interactions between PcCo with an aminophenoxy substituent and $\mathrm{NH}_{3}$, the high electrical conductivity of $\mathrm{rGO}$, and fast charge transfer between $\mathrm{PcCo}$ and $\mathrm{rGO}$. These are further confirmed via first-principle density functional theory (DFT) calculations and electrochemical impedance spectra (EIS) measurements.
\end{abstract}

\section{Introduction}

During the last few decades, gas sensors have boosted advances in agriculture, the food industry, industrial chemicals, and environmental and security areas. ${ }^{1-4}$ Obtaining highly selective, sensitive, cost-efficient and stable sensing materials is one of the key points for the development of new gas sensors for environmental and human health applications. Nanocomposite materials have recently attracted extensive interest for gas sensing applications due to synergetic and complementary effects. ${ }^{5-8}$ Among them, graphene and its nanocomposites, with two-dimensional $\mathrm{sp}^{2}$-hybridized carbon atoms, are currently, without any doubt, the most attractive gas sensing materials

${ }^{a}$ Key Laboratory of Functional Inorganic Material Chemistry, Ministry of Education, School of Chemistry and Materials Science, Heilongjiang University, Harbin 150080, P. R. China. E-mail: wangbin@hlju.edu.cn

${ }^{b}$ School of Material and Chemical Engineering, Heilongjiang Institute of Technology, Harbin 150050, P. R. China

${ }^{\prime} M I I T$ Key Laboratory of Critical Materials Technology for New Energy Conversion and Storage, School of Chemistry and Chemical Engineering, Harbin Institute of Technology, Harbin, P. R. China

${ }^{d}$ Shanghai Institute of Optics and Fine Mechanics, Chinese Academy of Sciences, Shanghai 201800, P. R. China

$\dagger$ Electronic supplementary information (ESI) available. See DOI: $10.1039 / \mathrm{c} 8 \mathrm{ra} 07509 \mathrm{c}$ due to their large specific surface areas and electron transport through them being highly sensitive to the absorption of gas molecules. ${ }^{9-15}$

In 2007, Novoselov's group reported the first graphene sensor for detecting gases. ${ }^{16}$ They showed that conductance changes in graphene are dependent on the nature of the gas molecules, which indicates that charge transfer between the gas molecules and graphene is responsible for the conductivity changes. This study has opened the door for a new type of gas sensor based on 2D graphene. While there are a few drawbacks relating to the limits of sensitivity and lack of selectivity with respect to graphene based sensors, defective and functionalized graphene may result in gas sensors with improved and efficient gas sensing performance, such as increased sensitivity, selectivity, response and recovery, through promoting charge transfer between graphene and the gas molecules. ${ }^{17-21}$ Owing to there being certain amounts of oxygen groups in reduced graphene oxide (rGO) that provide reactive sites for gas adsorption and further functionalization, rGO based gas sensors show improved sensing characteristics. Moreover, the conductance of such sensors can be restored through a chemical reduction process. ${ }^{10,22,23}$ The functionalization of rGO with functional materials (such as polymers, metals and metal oxide nanoparticles) has also been reported to improve its sensing efficiency. ${ }^{24-30}$ 
Metal phthalocyanines (MPcs) show improved sensing characteristics due to their $18 \pi$-conjugated skeletons, finetuned structures and high solubilities in solvents. ${ }^{31-34}$ However, the low conductivities of MPc based gas sensors have limited their practical applications. ${ }^{35}$ Importantly, MPcs are an ideal candidate for the functionalization of rGO, considering their possible further modification. ${ }^{36-39}$ The use of nanocomposites of MPcs and rGO may result in gas sensors with improved and efficient gas sensing characteristics, which may help to solve particular shortcomings through synergetic and complementary effects. Our group has reported gas sensors based on carbon nanotube (CNT)/MPc, graphene oxide (GO)/ MPc and rGO/MPc hybrids. ${ }^{\mathbf{4 0 - 4 2}}$ These sensors showed higher sensitivity toward $\mathrm{NH}_{3}$ than their carbon material counterparts. It was observed that the presence of functional MPcs played an important role in the sensing process. Nowadays there have been many studies reporting the effects of substituents on pristine MPcs for gas sensing, ${ }^{\mathbf{4 3 , 4 4}}$ but few systematic studies to date have reported the effects of substituent groups on the $\mathrm{NH}_{3}$ sensing characteristics of rGO/MPc hybrids. ${ }^{45}$

Considering the above-mentioned reasons, herein, we design three types of PcCo compound, tetra- $\alpha$ - $(p$-aminobenzyloxy)phthalocyanine cobalt (ABOPcCo) and tetra- $\alpha$-aminophthalocyanine cobalt, (APcCo) containing different amino substituents, and substituent-free phthalocyanine cobalt (FPcCo), and combine them with rGO functionalization to develop new high performance chemiresisitor-type $\mathrm{NH}_{3}$ sensors based on the ABOPcCo/rGO, APcCo/rGO and PcCo/rGO hybrids (as shown in Scheme 1). The PcCo/rGO sensors show better responses, and excellent selectivity and recovery characteristics in $\mathrm{NH}_{3}$ sensing. The gas sensing characteristics of the rGO based gas sensors are improved considerably due to the functionalization of rGO with PcCo.

\section{Experimental and calculation details}

\subsection{Reagents}

PcCo compounds were synthesized using 1,8-diazabicyclo[5,4,0] undec-7-ene (DBU) as a catalytic agent (the detailed process is

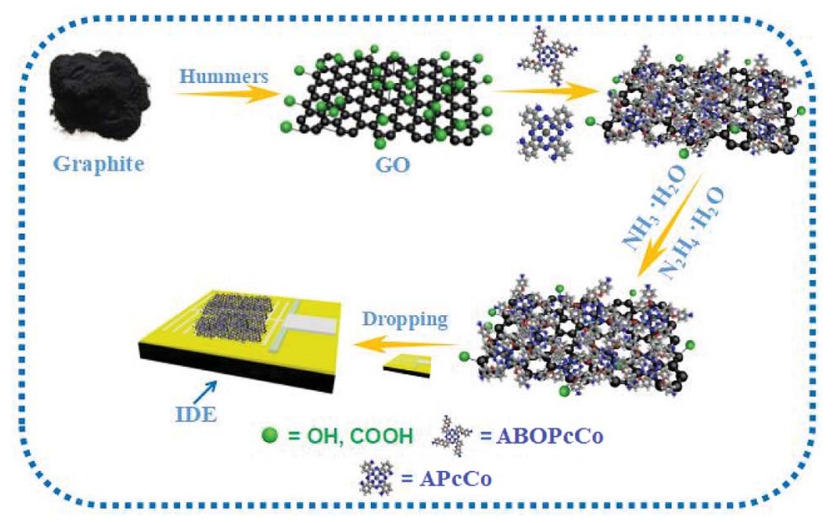

Scheme 1 Schematic diagram showing the preparation and $\mathrm{NH}_{3}-$ sensing of sensors composed of PcCo/rGO hybrids. shown in the ESI $\dagger$ ). Graphene oxide (GO) was used, as in our previous reports. ${ }^{\mathbf{4 1}}$ Ultrapure water was obtained using a Millipore Milli-Q system (Millipore Corp. Bedford, MA, USA). Graphite was purchased from Nanjing XFNANO Materials Tech Co., Ltd. 3-Nitrophthalonitrile (99\% purity) and DBU (98\% purity) were purchased from Sigma-Aldrich Co. LLC. All other reagents in this work were of analytical grade and used without further purification.

\subsection{Preparation of PcCo/rGO hybrids}

Two PcCo/rGO hybrids were prepared via the same general method: $20 \mathrm{ml}$ of $1.0 \mathrm{mg} \mathrm{ml}{ }^{-1}$ ABOPcCo DMF green solution was added dropwise to $10 \mathrm{ml}$ of $1.0 \mathrm{mg} \mathrm{ml}^{-1}$ GO DMF suspension. The mixtures were magnetically and ultrasonically stirred for $12 \mathrm{~h}$ under light-avoiding conditions. Then $3 \mathrm{ml}$ of ammonia and $0.03 \mathrm{ml}$ of hydrazine hydrate were added into the above reaction mixture, which was heated at $100{ }^{\circ} \mathrm{C}$ for $24 \mathrm{~h}$. The crude product was cooled to room temperature and washed several times successively, first with boiling water, and then with ethanol and tetrahydrofuran to remove impurities, until the filtrate was clear. The resulting black product was dried in vacuo for $12 \mathrm{~h}$ at $60{ }^{\circ} \mathrm{C}$. Other PcCo/rGO hybrids were prepared using the same method as given above.

\subsection{Sensor assembly and sensing measurements}

The gold interdigitated electrodes (IDEs) and gas sensor testing device used were as shown in our previous studies. ${ }^{40,41} \mathrm{PcCo} /$ rGO hybrids were dispersed $\left(0.5,1.0,1.5\right.$ and $\left.2.0 \mathrm{mg} \mathrm{ml}^{-1}\right)$ in DMF under ultrasonic waves for $2 \mathrm{~h}$. Then, $10 \mu \mathrm{l}$ of PcCo/rGO suspension was dropped onto the IDE gaps using a microsyringe. Sensor films were deposited after the solution was evaporated and dried in a vacuum oven for $2 \mathrm{~h}$ at $80{ }^{\circ} \mathrm{C}$. The sensor resistance was adjusted by varying the concentration of the PcCo/rGO hybrid in the DMF solution. For comparison, purified rGO and PcCo sensors were also obtained via the above methods.

The gas sensing performances of the sensors were measured with a CUST G2 gas sensing test system (Advanced Sensor Technology Laboratory of Jilin University, China). All measurements were performed at $28{ }^{\circ} \mathrm{C} \pm 1{ }^{\circ} \mathrm{C}$ with a relative humidity of $50 \% \pm 2 \%$. First, an air flow was introduced into the sensing test chamber to record a baseline. Then, target gases at certified concentrations were injected to register sensor signals. Finally, the sensor was recovered under an air flow. The humidity in the test chamber was controlled via changing the mixing ratio of fully humid air and dry air, and the humidity level was checked using a humidity sensor. In this experiment, we used a high purity concentration of $\mathrm{NH}_{3}$ gas (99.99\%) mixed with air as a carrier, using the static volumetric method to obtain a low concentration. The response is defined by the relative resistance change, as follows:

$$
\text { Response }(\%)=\frac{\Delta R}{R_{\mathrm{a}}} \times 100 \%=\frac{R_{\mathrm{g}}-R_{\mathrm{a}}}{R_{\mathrm{a}}} \times 100 \%
$$

where $R_{\mathrm{a}}$ and $R_{\mathrm{g}}$ are the sensor resistance values under the initial air flow, which was used as background, and under the 
target gas. The response and recovery times are defined as the times needed for $90 \%$ total resistance change upon exposure to the target gas and air, respectively. High purity $\mathrm{NH}_{3}$ gas was used as the $\mathrm{NH}_{3}$ source (Guangming Research and Design Institute of Chemical Industry, PR China).

\subsection{Characterization}

UV-vis absorption spectra were recorded with a UV-2700 spectrometer (SHIMADZU, Japan). Raman spectra, acquired using Raman spectroscopy, were obtained with a Jobin Yvon HR800 Raman spectrometer, using a $458 \mathrm{~nm}$ laser source. Scanning electron microscopy (SEM) images were recorded with a Hitachi S-4800 field emission scanning electron microscope operating at $15 \mathrm{kV}$. Samples were drop-deposited onto the interdigitated electrodes and examined directly. Transmission electron microscopy was performed with a JEM 2100 instrument at 200 $\mathrm{kV}$, utilizing a JEOL FasTEM system. Samples were dropped onto $\mathrm{Cu}$ grids with lacey carbon film and allowed to dry thoroughly before imaging. FT-IR spectra were recorded using a Spectrum Two spectrometer (PerkinElmer, USA). Electrochemical impedance spectra (EIS) were measured using a CHI600E electrochemical work station at room temperature (frequency range: $0.01 \mathrm{~Hz}$ to $100 \mathrm{kHz}$; at the open circuit potential with $5 \mathrm{mV}$ amplitude).

\subsection{Calculation details}

DFT calculations were performed for the adsorption of $\mathrm{NH}_{3}$ on PcCo compounds using the long-range corrected functional of CAM-B3LYP with a set of hybrid basis sets (LanL2DZ for metals and 6-31g(d) for $\mathrm{H}, \mathrm{C}$, and $\mathrm{N}) .{ }^{46}$ Charge analyses were performed using the NBO (natural bond orbital) method. ${ }^{47}$ The Gaussian 09 quantum chemical package was employed for all calculations in the present work. ${ }^{48}$

\section{Results and discussion}

\subsection{Characterization of $\mathrm{PcCo} / \mathrm{rGO}$ hybrids}

The surface morphologies of the $\mathrm{PcCo} / \mathrm{rGO}$ hybrids were characterized via TEM and SEM. The TEM images exhibit stacked few layered flakes with amorphous coatings (Fig. 1A and C), caused by the re-aggregation and folding of few layered graphene sheets and the functionalization of APcCo and ABOPcCo on the $\mathrm{rGO}$ surface. ${ }^{35} \mathrm{PcCo} / \mathrm{rGO}$ aqueous dispersions of $1.5 \mathrm{mg}$ $\mathrm{ml}^{-1}$ (Fig. 1E and F) were drop cast onto the IDEs. The PcCo/ rGO hybrids bridged gaps on the IDEs and provided the sensor with conductive and permeable channels for the diffusion of gas molecules (Fig. 1B and D). The SEM images also show that the $\mathrm{ABOPcCo} / \mathrm{rGO}$ sheet sizes range from $20-400 \mu \mathrm{m}^{2}$ and they are uniformly and loosely distributed between the two sides of the IDE; they are smaller and more even than those of $\mathrm{APcCo} / \mathrm{rGO}$. This agrees well with the surface morphologies of $\mathrm{PcCo} / \mathrm{rGO}$ sensors at other concentrations of $0.5,1.0$ and $2.0 \mathrm{mg}$ $\mathrm{ml}^{-1}$ (Fig. S2 $\dagger$ ), and can be attributed to the good dispersion of $\mathrm{ABOPcCo} / \mathrm{rGO}$ hybrids evolving from $\mathrm{ABOPcCo}$, containing four amine phenoxy groups, assembled on the surface of rGO. This is very useful in fabricating homogeneous gas sensors. Therefore,

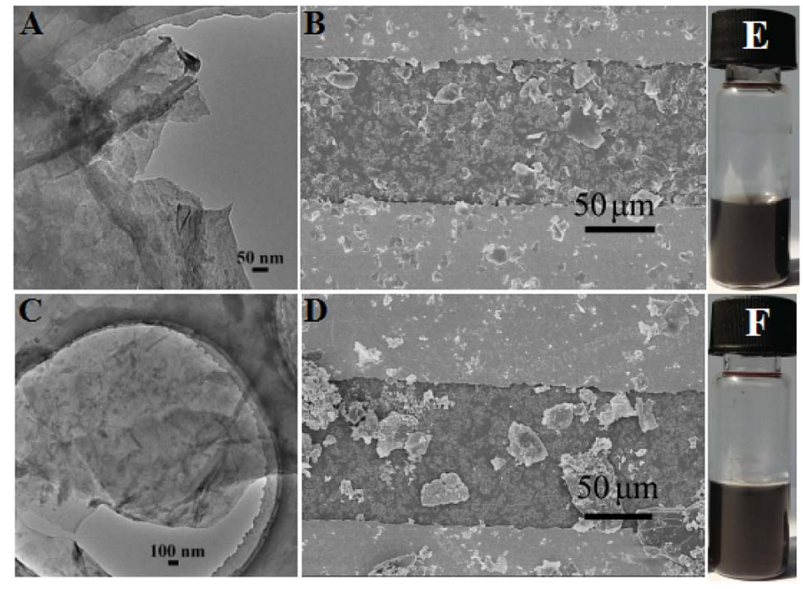

Fig. 1 ( $A$ and $C$ ) TEM images and ( $B$ and $D$ ) SEM images of ABOPcCo/ $\mathrm{rGO}$ and $\mathrm{APCCO} / \mathrm{rGO}$; and ( $E$ and $\mathrm{F}$ ) optical photographs of the equivalent $\mathrm{ABOPcCo} / \mathrm{rGO}$ and $\mathrm{APcCo} / \mathrm{rGO}$ hybrids dispersed in DMF after sonicating at room temperature for 20 minutes.

the influence of ABOPcCo and APcCo molecules on the dispersion of $\mathrm{PcCo} / \mathrm{rGO}$ hybrids was further observed. Fig. S3A and $\mathrm{B} \uparrow$ show that the $\mathrm{ABOPcCo} / \mathrm{rGO}$ and $\mathrm{APcCo} / \mathrm{rGO}$ hybrids have good dispersibility in DMF after sonicating. Surprisingly, the $\mathrm{ABOPcCo} / \mathrm{rGO}$ hybrid still exhibits excellent dispersibility, even after 2 months. The good dispersibility of the ABOPcCo/ rGO dispersion bridges the IDE gap more effectively, playing important roles in the adsorption of gases and electron transport. ${ }^{42,49,50}$

APcCo and ABOPcCo can be spontaneously loaded onto the surface of rGO via facile physical mixing, and the existence of $\mathrm{PcCo} / \mathrm{rGO}$ hybrids is further confirmed via IR spectra, UV-vis spectra and Raman spectroscopy. FT-IR spectra of rGO, $\mathrm{ABOPcCo}$ and $\mathrm{ABOPcCo} / \mathrm{rGO}$ hybrids are shown in Fig. 2A. The vibration peaks appearing at $1000-1650 \mathrm{~cm}^{-1}, 3334 \mathrm{~cm}^{-1}$ and $3222 \mathrm{~cm}^{-1}$, and $2930 \mathrm{~cm}^{-1}$ and $2856 \mathrm{~cm}^{-1}$ are characteristic phthalocyanine ring, amino group $\mathrm{N}-\mathrm{H}$ stretching and phenyl ring $\mathrm{C}-\mathrm{H}$ stretching peaks in $\mathrm{ABOPcCo}$, respectively. ${ }^{51}$ rGO shows its main characteristic peaks at $3419 \mathrm{~cm}^{-1}\left(\nu_{\mathrm{O}-\mathrm{H}}\right)$, $1634 \mathrm{~cm}^{-1}\left(\nu_{\mathrm{C}-\mathrm{OH}}\right)$ and $1080 \mathrm{~cm}^{-1}\left(\nu_{\mathrm{C}-\mathrm{O}-\mathrm{C}}\right){ }^{21}$ The stretching vibration peaks at about $3300 \mathrm{~cm}^{-1}, 2930 \mathrm{~cm}^{-1}$ and $1000-$ $1650 \mathrm{~cm}^{-1}$ belong to the characteristic fingerprint absorption peaks of N-H, C-H and the Pc ring of ABOPcCo in the ABOPcCo/ rGO hybrid. Moreover, the $\mathrm{APcCo} / \mathrm{rGO}$ hybrid shows a similar phenomenon in Fig. 2B. These results indicate that $\mathrm{PcCo} / \mathrm{rGO}$ hybrids have been obtained. The UV-vis spectra of rGO, PcCo
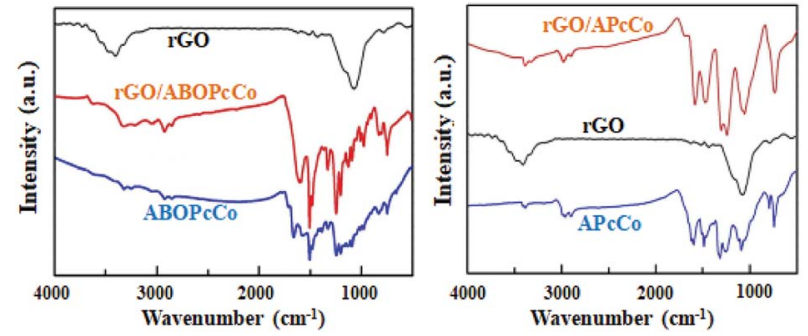

Fig. 2 FT-IR spectra of $\mathrm{rGO}$ and the PcCo and PcCo/rGO hybrids 

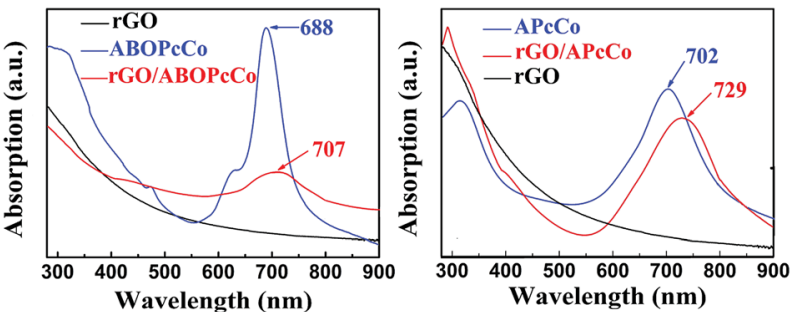

Fig. 3 UV-vis spectra of $\mathrm{rGO}$ and the PcCo and PcCo/rGO hybrids.

and PcCo/rGO hybrids in DMF are shown in Fig. 3. The absorption peaks at $702 \mathrm{~nm}$ and $688 \mathrm{~nm}$ are the characteristic Q-band absorption peaks of APcCo and ABOPcCo. The Q-band absorption peak of $\mathrm{ABOPcCo}$ is about $14 \mathrm{~nm}$ lower than that of APcCo. This is due to the introduction of an aminophenoxy substituent, which reduces the electron donor power of the amino substituent and increases the gap between the highest occupied molecular orbital (HOMO) and lowest unoccupied molecular orbital (LUMO). ${ }^{52}$ These peaks are broadened and shifted to higher wavenumbers (by about $27 \mathrm{~nm}$ and $19 \mathrm{~nm}$ ) in the $\mathrm{APcCo} / \mathrm{rGO}$ and $\mathrm{ABOPcCo} / \mathrm{rGO}$ hybrids. These results not only indicate that PcCo has been successfully loaded on rGO, but they also indicate that $\pi-\pi$ stacking between PcCo and rGO exists in the hybrids. ${ }^{52,53}$ The Raman spectrum is used as a finger-print for rGO. ${ }^{17}$ As shown in Fig. 4, the strong peaks appearing at 1364 and $1582 \mathrm{~cm}^{-1}$ are the characteristic D and G bands of rGO, respectively. The D band is related to structural defects caused by oxidation or the attachment of functional groups. The $\mathrm{G}$ band is related to first-order scattering of $\mathrm{E}_{2 \mathrm{~g}}$ symmetry. ${ }^{21}$ Compared with rGO, the Raman spectra of the $\mathrm{ABOPcCo} / \mathrm{rGO}$ and $\mathrm{APcCo} / \mathrm{rGO}$ hybrids are centered at 1360 and $1576 \mathrm{~cm}^{-1}$, and 1363 and $1575 \mathrm{~cm}^{-1}$, respectively, and are shifted to lower wavenumbers. Meanwhile, the $I_{\mathrm{D}} / I_{\mathrm{G}}$ values of the APcCo/rGO and ABOPcCo/rGO hybrids are 0.96 and 0.90 , which are smaller than that of rGO (0.98). This indicates that the functionalization of APcCo and ABOPcCo results in less defective sites. ${ }^{17}$ These results confirm that APcCo and ABOPcCo are functionalized onto the rGO surface successfully via a noncovalent approach.

\section{2 $\mathrm{NH}_{3}$ sensing properties of the PcCo/rGO hybrids}

The amount of PcCo/rGO hybrid bridging the IE gap and the resistance of the PcCo/rGO sensors can be controlled using via the concentrations of $\mathrm{ABOPcCo} / \mathrm{rGO}$ and $\mathrm{APcCo} / \mathrm{rGO}$ aqueous dispersions. Table $\mathrm{S} 1 \dagger$ shows that the resistance values of the $\mathrm{PcCo} / \mathrm{rGO}$ sensors are related to the concentrations of $\mathrm{PcCo} / \mathrm{rGO}$ aqueous dispersions, as taken from Fig. 5A and C. For example, the $\mathrm{ABOPcCo} / \mathrm{rGO}$ sensors show resistances of $2.38 \pm 0.50,0.71$ $\pm 0.05,0.07 \pm 0.05$ and $0.06 \pm 0.05 \mathrm{M} \Omega$ with $\mathrm{ABOPcCo} / \mathrm{rGO}$ aqueous dispersion concentrations of $0.5,1.0,1.5$, and $2.0 \mathrm{mg}$ $\mathrm{ml}^{-1}$, respectively (Fig. 5A). As has been shown, the resistance value of the PcCo/rGO sensor changes inversely to the concentration of $\mathrm{PcCo} / \mathrm{rGO}$ aqueous dispersion. The higher the concentration of the $\mathrm{ABOPcCo} / \mathrm{rGO}$ aqueous dispersion, the more $\mathrm{ABOPcCo} / \mathrm{rGO}$ hybrid bridges the IDE gap, leading to reduced sensor resistance. ${ }^{21}$ More importantly, the $\mathrm{NH}_{3}$ sensing

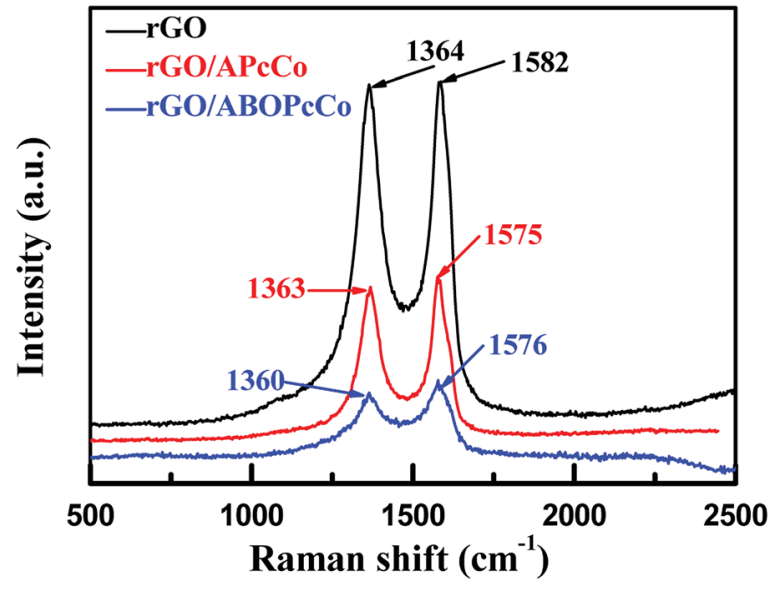

Fig. 4 Raman spectra of $\mathrm{rGO}$ and the PcCo/rGO hybrids, obtained at $\lambda_{\text {exc }}=457.9 \mathrm{~nm}$.

performance is related to the resistance values of the $\mathrm{PcCo} / \mathrm{rGO}$ hybrids. It was found that the response increased first and then decreased as the resistance of the $\mathrm{PcCo} / \mathrm{rGO}$ sensor decreased at $28{ }^{\circ} \mathrm{C}$ (Fig. 5B and D). The PcCo/rGO aqueous dispersion with a concentration of $1.5 \mathrm{mg} \mathrm{ml} \mathrm{m}^{-1}$ led to the preparation of a sensor showing excellent $\mathrm{NH}_{3}$ sensing performance. Therefore, this concentration was used to prepare sensors for gas sensing applications. The amount of $\mathrm{PcCo} / \mathrm{rGO}$ hybrid bridging the IDE gap, and the number of absorption sites of PcCo/rGO for $\mathrm{NH}_{3}$ increase with an increase in the concentration of $\mathrm{PcCo} / \mathrm{rGO}$ aqueous dispersion at low concentrations. However, a high concentration of $\mathrm{PcCo} / \mathrm{rGO}$ reduces aqueous dispersion, leading to aggregation and reduced gas sensing performance.

As a control, the sensing responses of rGO and PcCo molecules towards $\mathrm{NH}_{3}$ were also studied. The response intensities are poor for the rGO and PcCo sensors (Fig. S4 $\uparrow$ ). The rGO sensor shows poor recovery properties, and the resistance of the
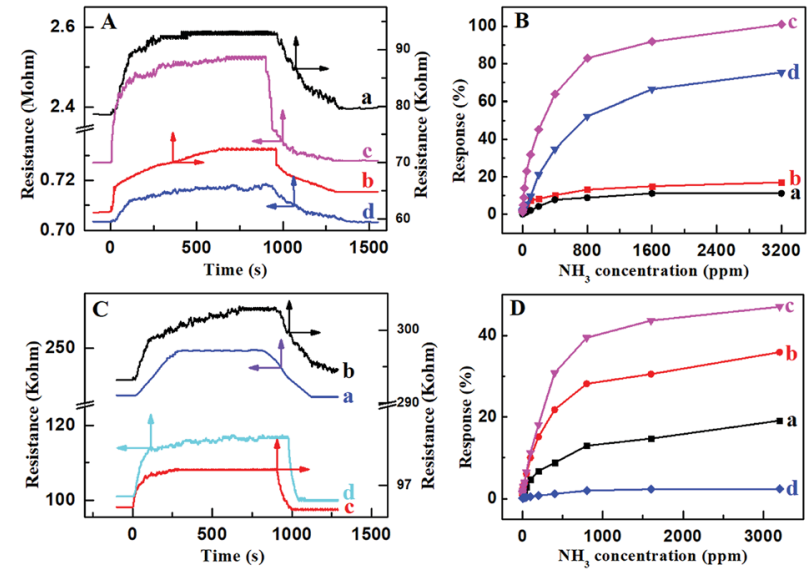

Fig. 5 The resistance of (A) ABOPcCo/rGO and (C) APcCo/rGO hybrid sensors upon exposure to $50 \mathrm{ppm} \mathrm{NH}_{3}$ with $\mathrm{PcCo} / \mathrm{rGO}$ aqueous dispersion concentrations of (a) 0.5 , (b) 1.0 , (c) 1.5 , and (d) $2.0 \mathrm{mg} \mathrm{ml}^{-1}$, respectively, at $28^{\circ} \mathrm{C}$; and the relationship between the response of (B) $\mathrm{ABOPcCO} / \mathrm{rGO}$ and (D) APcCo/rGO hybrid sensors and the concentration of $\mathrm{NH}_{3}$ with $\mathrm{PcCO} / \mathrm{rGO}$ aqueous dispersion concentrations of (a) 0.5 , (b) 1.0 , (c) 1.5 , and (d) $2.0 \mathrm{mg} \mathrm{ml}^{-1}$, respectively, at $28{ }^{\circ} \mathrm{C}$. 
rGO sensor can't even recover its original resistance within an hour with an increase in the $\mathrm{NH}_{3}$ concentration. By contrast, the $\mathrm{PcCo} / \mathrm{rGO}$ sensors exhibit remarkable response and recovery performances towards $\mathrm{NH}_{3}$, especially the ABOPcCo/rGO sensor. For example, the ABOPcCo/rGO sensor shows a response of $23.3 \%$ to $50 \mathrm{ppm} \mathrm{NH}_{3}$ gas (Fig. $5 \mathrm{~B}$ ), which is over 7 times and 15 times higher than the rGO and ABOPcCo sensors, respectively. The response and recovery times of the $\mathrm{ABOPcCo} /$ $\mathrm{rGO}$ and $\mathrm{APcCo} / \mathrm{rGO}$ sensors to $50 \mathrm{ppm} \mathrm{NH}_{3}$ are $225 \mathrm{~s}$ and $225 \mathrm{~s}$, and $80 \mathrm{~s}$ and $250 \mathrm{~s}$, respectively, at $28{ }^{\circ} \mathrm{C}$ (Fig. S5 $\dagger$ ). Additionally, it is clear that the response of the $\mathrm{ABOPcCo} / \mathrm{rGO}$ sensor is higher than that of the APcCo/rGO sensor (Fig. 5B and D). For example, the $\mathrm{ABOPcCo} / \mathrm{rGO}$ sensor shows a 3.6 times higher response to $50 \mathrm{ppm} \mathrm{NH}_{3}$ gas than the APcCo/rGO sensor. The responses of the $\mathrm{PcCo} / \mathrm{rGO}$ sensors to $\mathrm{NH}_{3}$ gas concentrations in the range of 3-50 ppm were approximately linear (Fig. S6 $\dagger$ ). For $\mathrm{ABOPcCo} / \mathrm{rGO}$, the slope of the linear fit was $0.421 \mathrm{ppm}^{-1}$ and the correlation coefficient $\left(R^{2}\right)$ was 0.979 . The limit of detection (LOD) was estimated to be $78 \mathrm{ppb}$ at $28{ }^{\circ} \mathrm{C}(\mathrm{S} / \mathrm{N}=3)$, according to eqn (2):

$$
\operatorname{LOD}(\mathrm{ppm})=3 \times \frac{\mathrm{RMS}_{\text {noise }}}{\text { slope }}
$$

where $\mathrm{RMS}_{\text {noise }}$ is the standard deviation of the noise, which is calculated to be equal to 0.01 based on 11 data points from the baseline of the response curve. ${ }^{54}$ Similarly, the LOD of APcCo/ rGO was estimated to be $1.3 \mathrm{ppm}$ at $28{ }^{\circ} \mathrm{C}$. In order to certify the effects of substituents on gas sensing properties, the gas sensing properties of $\mathrm{PcNi} / \mathrm{rGO}$ were also studied. Fig. S7† shows the relationship between the responses of the PcNi/rGO hybrid sensors and the concentration of $\mathrm{NH}_{3}$. Similar to PcCo/ $\mathrm{rGO}$, the $\mathrm{ABOPcNi} / \mathrm{rGO}$ sensor also shows a better response than the APcNi/rGO sensor.

Fig. 6A shows the selectivity of $\mathrm{rGO}, \mathrm{ABOPcCo} / \mathrm{rGO}$ and APcCo/rGO sensors towards several normal gas samples $\left(\mathrm{NH}_{3}\right.$ and $\mathrm{NO}_{x}$ : $50 \mathrm{ppm}$; other gases: $3200 \mathrm{ppm}$ ) and volatile organic compounds (VOCs: $3200 \mathrm{ppm}$ ) at different humidity levels at $28{ }^{\circ} \mathrm{C}$. The responses of the rGO sensor to $\mathrm{NH}_{3}, \mathrm{NO}_{x}, \mathrm{EtOH}$, $\mathrm{MeOH}, \mathrm{PA}$ and $90 \% \mathrm{RH}$, other gases and VOCs are $3.2 \%, 2 \%$, $1.5 \%, 1 \%, 1 \%$ and lower than $1 \%$, respectively. Surprisingly, the responses of the ABOPcCo/rGO and APcCo/rGO sensors to $\mathrm{NH}_{3}$ increase to $23.3 \%$ and $6.4 \%$, but the responses to other gases and different relative humidity levels are still less than $2 \%$. It should be pointed out that the PcCo/rGO sensors exhibit high responses to $\mathrm{NH}_{3}$ and low responses to $\mathrm{NO}_{x}$ at the same concentration (50 ppm), which is usually not easily achieved. The results demonstrate that the functionalization of APcCo and ABOPcCo on rGO offers a very effective way to tune and boost the gas sensing performance, such as producing improved responses and selectivities.

Fig. 6B shows the long-term stabilities of the $\mathrm{ABOPcCo} / \mathrm{rGO}$ and $\mathrm{APcCo} / \mathrm{rGO}$ sensors upon exposure to $200 \mathrm{ppm}$ and 50 ppm $\mathrm{NH}_{3}$ over 30 days at $28{ }^{\circ} \mathrm{C}$. The responses of the $\mathrm{ABOPcCo} / \mathrm{rGO}$ and $\mathrm{APcCo} / \mathrm{rGO}$ sensors up to 30 days reduced by less than $5 \%$, indicating that the PcCo/rGO sensors display excellent long-term stability. Meanwhile, the ABOPcCo/rGO sensor also displays 3.6 and 2.4 times higher responses to
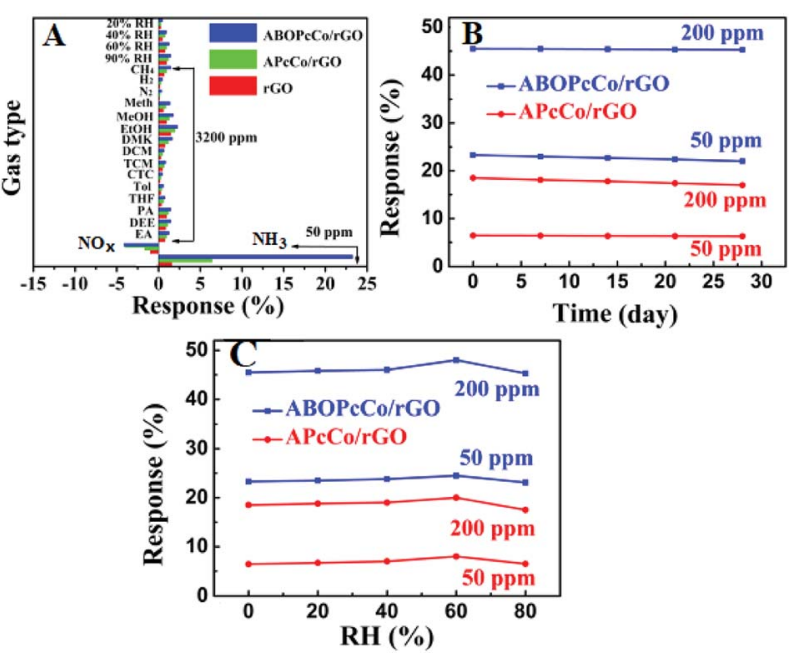

Fig. 6 (A) Cross-sensitivities to various gases shown by the $\mathrm{rGO}$ and $\mathrm{PcCO} / \mathrm{rGO}$ hybrid sensors: $\mathrm{MeTH}=$ methanal; $\mathrm{MeOH}=$ methanol; $\mathrm{EtOH}=$ ethanol; $\mathrm{DMK}=$ acetone; $\mathrm{DCM}=$ dichloromethane; $\mathrm{TCM}=$ trichloromethane; $\mathrm{CTC}=$ carbon tetrachloride; $\mathrm{Tol}=$ toluene; $\mathrm{THF}=$ tetrahydrofuran; $\mathrm{PA}=$ propionic acid; $\mathrm{DEE}=$ diethyl ether; and $\mathrm{EA}=$ ethyl acetate; (B) the responses of PcCo/rGO hybrid sensors to 50 and 200 ppm $\mathrm{NH}_{3}$ over long-term storage; and (C) the responses of PcCo/ rGO hybrid sensors upon exposure to 50 and $200 \mathrm{ppm} \mathrm{NH}_{3}$ at different relative humidity levels at $28^{\circ} \mathrm{C}$.

$50 \mathrm{ppm}$ and $200 \mathrm{ppm} \mathrm{NH}_{3}$, respectively, than the APcCo/rGO sensor. Moreover, the effects of humidity on the $\mathrm{NH}_{3}$-sensing properties of the PcCo/rGO sensors were also studied. Fig. 6C shows the responses of the $\mathrm{ABOPcCo} / \mathrm{rGO}$ and $\mathrm{APcCo} / \mathrm{rGO}$ hybrid sensors upon exposure to $200 \mathrm{ppm}$ and $50 \mathrm{ppm} \mathrm{NH}_{3}$ at different relative humidity levels at $28{ }^{\circ} \mathrm{C}$. As can be seen, the responses of the PcCo/rGO sensors did not change obviously below $60 \%$ RH. However, the response decreases under a high $\mathrm{RH}$ of $80 \%$, which might be ascribed to competitive adsorption between $\mathrm{NH}_{3}$ and $\mathrm{H}_{2} \mathrm{O}$ molecules. ${ }^{55,56}$

Fig. 7 displays the dynamic resistance curves of $\mathrm{PcCo} / \mathrm{rGO}$ sensors upon exposure to different $\mathrm{NH}_{3}$ concentrations, from $3200 \mathrm{ppm}$ to $750 \mathrm{ppb}$, and in $200 \mathrm{ppm} \mathrm{NH}_{3}$ gas over ten continuous cycles at $28{ }^{\circ} \mathrm{C}$. The resistance goes through a rapid increase followed by a slow increase in $\mathrm{NH}_{3}$ gas. Then, the resistance sharply decreases when the sensors are exposed to air again (Fig. 7A and C). The sensors can detect relatively low concentrations of $\mathrm{NH}_{3}$, as low as $78 \mathrm{ppb}$. Fig. 7B and D show dynamic resistance curves over ten cycles of exposing the $\mathrm{ABOPcCo} / \mathrm{rGO}$ and APcCo/rGO sensors to $200 \mathrm{ppm} \mathrm{NH}_{3}$. The resistance curves show similar continuous recycling and the error is less than $3 \%$ over ten continuous cycles. The sensor shows a fast recovery time. Clearly, the PcCo/rGO sensors have good stability and repeatability, which are crucial for further applications. The high sensitivities, low detection limits and fast response and recovery times of our $\mathrm{NH}_{3}$ sensors are also significantly superior to previously reported sensors (as shown in Table $\mathrm{S} 2 \dagger$ ).

To obtain further insight into the effects of amino substituents on gas sensing properties, a substituent-free phthalocyanine cobalt/rGO (FPcCo/rGO) hybrid was synthesized via noncovalent interactions. The dynamic response, 

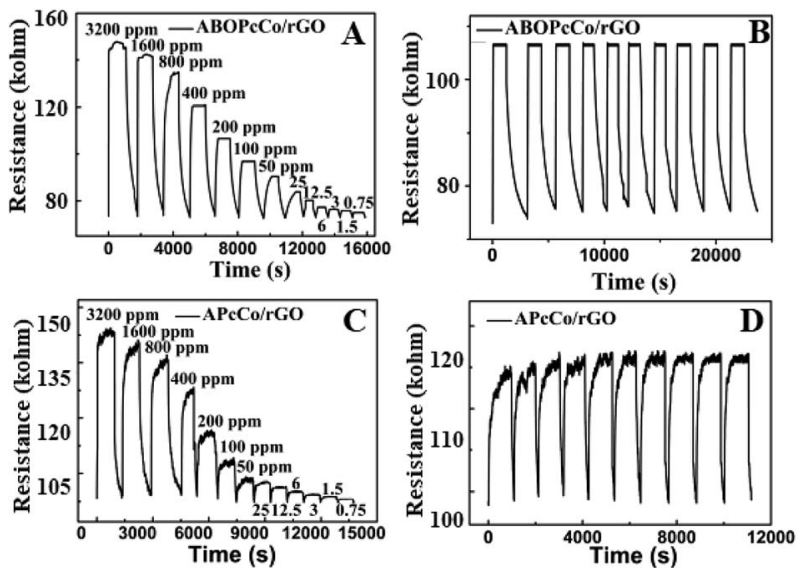

Fig. 7 The resistance of (A) ABOPcCo/rGO and (C) APcCo-rGO hybrid sensors upon exposure to varying concentrations of $\mathrm{NH}_{3}$ with a $\mathrm{PcCO} /$ $\mathrm{rGO}$ aqueous dispersion concentration of $1.5 \mathrm{mg} \mathrm{m}^{-1}$; and ten sensing cycles of (B) ABOPcCo/rGO and (D) APcCo-rGO hybrid sensors being exposed to $200 \mathrm{ppm} \mathrm{NH}_{3}$ with a $\mathrm{PcCo} / \mathrm{rGO}$ aqueous dispersion concentration of $1.5 \mathrm{mg} \mathrm{ml}^{-1}$ at $28^{\circ} \mathrm{C}$.

reproducibility, and relationship between the response of the $\mathrm{PcCo} / \mathrm{rGO}$ sensor and the concentration of $\mathrm{NH}_{3}$ were also investigated (as shown in Fig. S8†). It's clear that the response of the $\mathrm{FPcCo} / \mathrm{rGO}$ sensor increases as the concentration of $\mathrm{NH}_{3}$ is increased. Although the $\mathrm{FPcCo} / \mathrm{rGO}$ sensor exhibits fast response and recovery times and good reproducibility, its response is so much lower than those of the $\mathrm{ABOPcCo} / \mathrm{rGO}$ and $\mathrm{APcCo} / \mathrm{rGO}$ sensors that no response can be observed at concentrations less than 12.5 ppm NH $\mathrm{NH}_{3}$. As shown in Fig. S8D, $\dagger$ the responses of the various sensors decrease in the order: $\mathrm{ABOPcCo} / \mathrm{rGO}>\mathrm{APcCo} / \mathrm{rGO}>\mathrm{FPcCo} / \mathrm{rGO}>\mathrm{rGO}$. Owing to the same central metal phthalocyanine loading, the discrepancies in responses are mainly due to differences between the PcCo compounds or, to be more specific, the substituents, for example, the electron donating ability and the electron cloud density, especially interaction effects between $\mathrm{NH}_{3}$ and different PcCo compounds. Amino groups have stronger electrondonating capabilities. They can provide more electrons to combine with the holes in the p-type semiconductors of PcCo and rGO. The combination of electrons and holes can reduce charge transfer between $\mathrm{APcCo} / \mathrm{rGO}$ and the adsorbed gas molecules, reducing $\mathrm{NH}_{3}$ gas and leading to further speeding up the recovery time. On the contrary, aminophenoxy groups have weaker electron-donating capabilities than amino groups. This can improve charge transfer between $\mathrm{ABOPcCo} / \mathrm{rGO}$ and the adsorbed gas molecules, reducing $\mathrm{NH}_{3}$ gas and leading to a further increase in the gas response. ${ }^{38}$ These results further indicate that the substituents of PcCo molecules are of primary importance in tuning the gas sensing performance. The effects of amino substituents on the sensing properties will be discussed using DFT studies.

\subsection{The $\mathrm{NH}_{3}$ sensing mechanism of PcCo/rGO hybrids}

The $\mathrm{NH}_{3}$ sensing mechanism of the $\mathrm{PcCo} / \mathrm{rGO}$ hybrids is based on the resistance changes of the $\mathrm{PcCo} / \mathrm{rGO}$ sensors upon exposure to $\mathrm{NH}_{3}$, which are attributed to charge transfer between $\mathrm{PcCo} / \mathrm{rGO}$ and adsorbed gas molecules. A reducing gas $\left(\mathrm{NH}_{3}\right)$ donates electrons to $\mathrm{PcCo} / \mathrm{rGO}$, which could lead to a decrease in charge carriers (holes) and an increase in the electrical resistance of the hybrid (Fig. 5 and 7). This hypothesis is further confirmed upon interaction with an oxidizing gas, such as $\mathrm{NO}_{2}$. An oxidizing gas $\left(\mathrm{NO}_{2}\right)$ withdraws electrons from $\mathrm{PcCo} / \mathrm{rGO}$, which could lead to a contrary change in the electrical resistance of a hybrid (Fig. 6A). ABOPcCo and APcCo loaded rGO hybrids display improved $\mathrm{NH}_{3}$ sensing performances, which are attributed to the following factors. Firstly, rGO as a conductive agent has a large specific surface area and high carrier mobility and plays an important role in the electronic properties of $\mathrm{PcCo} / \mathrm{rGO}$ hybrids, which show great promise for sensor performance enhancement. Secondly, the functionalization of APcCo and ABOPcCo on the surface of rGO offers more active $\mathrm{NH}_{3}$ sensing sites. Meanwhile, the amino groups of APcCo, as a stronger electron-donating group, provide more electrons to combine with the holes in the p-type semiconductors of APcCo and rGO, weakening charge transfer between $\mathrm{APcCo} / \mathrm{rGO}$ and adsorbed gas molecules, reducing $\mathrm{NH}_{3}$ gas and accelerating the recovery time. On the contrary, the aminophenoxy groups of ABOPcCo weaken the donation power, decreasing the combination of electrons and holes and increasing charge transfer between $\mathrm{ABOPcCo} / \mathrm{rGO}$ and adsorbed gas molecules; this reduces $\mathrm{NH}_{3}$ gas and enhances the $\mathrm{NH}_{3}$ sensing response of $\mathrm{ABOPcCo} / \mathrm{rGO}$ for $\mathrm{NH}_{3}$ molecules, decreasing the recovery ability. These results show promise in tuning the sensitivity and recovery performance of rGO-based gas sensors, which was confirmed via DFT calculations. Due to less interaction between $\mathrm{NH}_{3}$ and $\mathrm{rGO}$, only the interactions between $\mathrm{NH}_{3}$ and PcCo molecules were calculated. Table 1 shows the net charge on the $\mathrm{NH}_{3}$ moiety and the distance between cobalt and $\mathrm{NH}_{3}$. Fig. $\mathrm{S} 9 \dagger$ shows the structures of adsorbed $\mathrm{NH}_{3}-\mathrm{PcCo}$ molecules, with top and side views. The smaller the distance between cobalt and $\mathrm{NH}_{3}$, the larger the net charge on $\mathrm{NH}_{3}$, the greater the charge transfer between PcCo and $\mathrm{NH}_{3}$ gas, and the better the gas sensing performance of $\mathrm{PcCo} / \mathrm{rGO}$ for $\mathrm{NH}_{3}$. The distance in $\mathrm{ABOPcCo}-\mathrm{NH}_{3}$ is shorter, and the net charge on the $\mathrm{NH}_{3}$ moiety is larger than that for APcCo- $\mathrm{NH}_{3}$ and $\mathrm{FPcCo}-\mathrm{NH}_{3}$, so the $\mathrm{NH}_{3}$ sensing properties of $\mathrm{ABOPcCo} / \mathrm{rGO}$ are better than those of $\mathrm{APcCo} / \mathrm{rGO}$ and $\mathrm{FPcCo} /$ rGO. Thirdly, charge transfer between PcCo and rGO can be achieved via $\pi-\pi$ stacking interactions, which can accelerate charge transfer between the $\mathrm{PcCo} / \mathrm{rGO}$ hybrids and adsorbed $\mathrm{NH}_{3}$ molecules. In order to verify the electron transportation abilities, electrochemical impedance spectroscopy (EIS) data of PcCo and PcCo/rGO hybrids were studied (Fig. S10†). The

Table 1 Calculated adsorption energies, major bond distances, and net charges in the adsorption of $\mathrm{NH}_{3}$ on the PcCo examples

\begin{tabular}{lll}
\hline Sub. $^{a}$ & Net charge $^{b}$ & $d(\mathrm{M}-\mathrm{R})^{c}(\AA)$ \\
\hline ABOPcCo & 0.168 & 2.214 \\
APcCo & 0.162 & 2.216 \\
PcCo & 0.160 & 2.240
\end{tabular}

${ }^{a}$ Substrate. ${ }^{b}$ The net charge on $\mathrm{NH}_{3} .{ }^{c}$ The distance between the metal and $\mathrm{NH}_{3}$. 
semicircle in the high-frequency range for $\mathrm{PcCo} / \mathrm{rGO}$ is smaller than that of PcCo, which corresponds to the charge transfer resistance $\left(R_{\mathrm{ct}}\right.$ in Table $\left.\mathrm{S} 3 \dagger\right) . R_{\mathrm{ct}}$ is related to electron transportation in the gas sensor. The lower the value of $R_{\mathrm{ct}}$, the stronger the electron transport. The $R_{\mathrm{ct}}$ values of the $\mathrm{PcCo} / \mathrm{rGO}$ hybrids are lower than that of PcCo. The electrons can easily transfer from $\mathrm{NH}_{3}$ to $\mathrm{PcCo} / \mathrm{rGO}$. Moreover, the $R_{\mathrm{ct}}$ value of $\mathrm{ABOPcCo} / \mathrm{rGO}$ is much lower than that of APcCo/rGO. Therefore, the ABOPcCo/rGO sensor displays better $\mathrm{NH}_{3}$ sensing performance.

\section{Conclusions}

Three $\mathrm{NH}_{3}$ gas sensors based on ABOPcCo/rGO, APcCo/rGO and FPcCo/rGO hybrids have been fabricated with significantly improved sensitivities, selectivities and recoveries through optimizing the concentration of a $\mathrm{PcCo} / \mathrm{rGO}$ aqueous dispersion. For example, compared with pure rGO, ABOPcCo/rGO, $\mathrm{APcCo} / \mathrm{rGO}$ and FPcCo/rGO hybrids showed twenty-three-fold, six-fold and two-fold higher responses to $50 \mathrm{ppm} \mathrm{NH}_{3}$, respectively, and improved recovery times for $\mathrm{NH}_{3}$ sensing. Additionally, the performances of the PcCo/rGO hybrids may be tuned by adjusting the PcCo substituent. Compared with many existing $\mathrm{NH}_{3}$ sensors, the obtained sensors, especially the ABOPcCo/rGO sensor $\left(23.3 \%\right.$ to $50 \mathrm{ppm} \mathrm{NH}_{3}$, with a LOD of $78 \mathrm{ppb}$ and a $250 \mathrm{~s}$ recovery time), exhibit better responses. These performances are mainly ascribed to: (a) the aminophenoxy groups reducing the electron donation power of the amino groups and increasing the charge transfer between $\mathrm{PcCo} /$ rGO and $\mathrm{NH}_{3}$; (b) rGO providing high conductivity and continuous pathways for charge transportation; and (c) PcCo/rGO hybrids showing excellent electron transportation abilities. EIS and DFT calculations confirm that the aminophenoxy groups of PcCo play a critical role in the $\mathrm{NH}_{3}$ sensing performance. This systematic study provides a valid way to improve the performances of rGO based $\mathrm{NH}_{3}$ sensors.

\section{Conflicts of interest}

There are no conflicts to declare.

\section{Acknowledgements}

We gratefully acknowledge financial support from the National Natural Science Foundation of China (51202061 and 51002046), the Innovative Talents Program of Harbin (2017RAQXJ143), the Opening Project Foundation of the Key Laboratory of Functional Inorganic Material Chemistry (Heilongjiang University), and the Ministry of Education.

\section{References}

1 S. W. Lee, W. Lee, Y. Hong, G. Lee and D. S. Yoon, Sens. Actuators, B, 2018, 255, 1788.

2 J. Zhang, Z. Y. Qin, D. Zeng and C. Xie, Phys. Chem. Chem. Phys., 2017, 19, 6313.
3 N. R. Tanguy, M. Thompson and N. Yan, Sens. Actuators, B, 2018, 257, 1044.

4 S. S. Varghese, S. Lonkar, K. K. Singh, S. Swaminathan and A. Abdala, Sens. Actuators, B, 2015, 218, 160.

5 A. kaushik, R. Kumar, S. K. Arya, M. Nair, B. D. Malhotra and S. Bhansali, Chem. Rev., 2015, 115, 4571.

6 G. Korotcenkov and B. K. Cho, Sens. Actuators, B, 2017, 244, 182.

7 J. P. Cheng, J. Wang, Q. Q. Li, H. G. Liu and Y. Li, J. Ind. Eng. Chem., 2016, 44, 1.

8 L. Zhu and W. Zeng, Sens. Actuators, A, 2017, 267, 242.

9 S. Mao, G. H. Lu and J. H. Chen, J. Mater. Chem. A, 2014, 2, 5573.

10 W. J. Yuan and G. Q. Shi, J. Mater. Chem. A, 2013, 1, 10078. 11 V. Georgakilas, M. Otyepka, A. B. Bourlinos, V. Chandra, N. Kim, K. C. Kemp, P. Hobza, R. Zboril and K. S. Kim, Chem. Rev., 2012, 112, 6156.

12 F. Perreault, A. Fonseca de Faria and M. Elimelech, Chem. Soc. Rev., 2015, 44, 5861.

13 E. Llobet, Sens. Actuators, B, 2013, 179, 32.

14 J. W. Wei, B. Liang, Q. P. Cao, C. T. Mo, Y. M. Zheng and X. S. Ye, $R S C A d v ., 2017,7,33510$.

15 F. Khurshid, M. Jeyavelan, K. Takahashi, M. Sterlin Leo Hudson and S. Nagarajan, RSC Adv., 2018, 8, 20440.

16 F. Schedin, A. K. Geim, S. V. Morozov, E. W. Hill, P. Blake, M. I. Katsnelson and K. S. Novoselov, Nat. Mater., 2007, 6, 652.

17 X. Wang, X. Li, Y. Zhao, Y. Chen, J. Yu and J. Wang, RSC Adv., 2016, 6, 52339.

18 X. L. Wei, Y. P. Chen, W. L. Liu and J. X. Zhong, Phys. Lett. A, 2012, 376, 559.

19 A. Salehi-Khojin, D. Estrada, K. Y. Lin, M. H. Bae, F. Xiong, E. Pop and R. I. Masel, Adv. Mater., 2012, 24, 53.

20 H. Y. Zhao, S. Q. Fan, Y. Chen, Z. H. Feng, H. Zhang, W. Pang, D. H. Zhang and M. L. Zhang, ACS Appl. Mater. Interfaces, 2017, 9, 40774.

21 J. Wu, K. Tao, J. Zhang, Y. Y. Guo, J. M. Miao and L. K. Norford, J. Mater. Chem. A, 2016, 4, 8130.

22 F. Yavari and N. Koratka, J. Phys. Chem. Lett., 2012, 3, 1746. 23 S. Zhang, D. Zhang, V. I. Sysoev, O. V. Sedelnikova, I. P. Asanov, M. V. Katkov, H. H. Song, A. V. Okotrub, L. G. Bulusheva and X. H. Chen, RSC Adv., 2014, 4, 46930.

24 Y. Yang, L. Sun, X. T. Dong, H. Yu, T. T. Wang, J. X. Wang, R. H. Wang, W. S. Yu and G. X. Liu, RSC Adv., 2016, 6, 37085.

25 I. Karaduman, E. Er, H. Çelikkan, N. Erk and S. Acar, J. Alloys Compd., 2017, 722, 569.

26 N. M. Triet, L. T. Duy, B. Hwang, A. Hanif, S. Siddiqui, K. Park, C. Y. Cho and N. E. Lee, ACS Appl. Mater. Interfaces, 2017, 9, 30722.

27 X. L. Huang, N. T. Hu, R. G. Gao, Y. Yu, Y. Y. Wang, Z. Yang, et al., J. Mater. Chem., 2012, 22, 22488.

28 Y. J. Yang, X. J. Yang, W. Y. Yang, S. B. Li, J. H. Xu and Y. D. Jiang, RSC Adv., 2014, 4, 42546.

29 X. L. Huang, N. T. Hu, Y. Y. Wang and Y. F. Zhang, Leading Edge of Micro-Nano Science and Technology, 2013, vol. 669, p. 79. 
30 Z. B. Ye, Y. D. Jiang, H. L. Tai and Z. Yuan, Integr. Ferroelectr., 2014, 154, 73.

31 A. Kumar, N. Joshi, S. Samanta, A. Singh, A. K. Debnath, A. K. Chauhan, M. Roy, R. Prasad, K. Roy, M. M. Chehimi, D. K. Aswal and S. K. Gupta, Sens. Actuators, B, 2015, 206, 653.

32 A. Kumar, J. Brunet, C. Varenne, A. Ndiaye, A. Pauly, M. Penza and M. Alvisi, Sens. Actuators, B, 2015, 210, 398.

33 T. Sizun, M. Bouvetn and J. Suisse, Talanta, 2012, 97, 318.

34 Y. Y. Wang, N. T. Hu, Z. H. Zhou, D. Xu, Z. Wang, Z. Yang, H. Wei, E. S. W. Kong and Y. F. Zhang, J. Mater. Chem., 2011, 21, 3779.

35 M. Ragoussi, J. Malig, G. Katsukis, B. Butz, E. Spiecker, G. Torre, T. Torres and D. M. Guldi, Angew. Chem., Int. Ed., 2012, 51, 6421.

36 J. H. Zhu, Y. X. Li, Y. Chen, J. Wang, B. Zhang, J. J. Zhang and W. J. Blau, Carbon, 2011, 49, 1900.

37 N. Karousis, J. Ortiz, K. Ohkubo, T. Hasobe, S. Fukuzumi, Á. Sastre-Santos and N. Tagmatarchis, J. Phys. Chem. C, 2012, 116, 20564.

38 H. Wu, Z. M. Chen, J. L. Zhang, F. Wu, C. Y. He, B. Wang, Y. Q. Wu and Z. Y. Ren, J. Mater. Chem. A, 2016, 4, 1096.

39 F. D'Souza and O. Ito, Chem. Commun., 2009, 4913.

40 X. Q. Zhou, X. L. Wang, B. Wang, Z. M. Chen, C. Y. He and Y. Q. Wu, Sens. Actuators, B, 2014, 193, 340.

41 Y. Li, B. Wang, Z. Y. Yu, X. Q. Zhou, D. Kang, Y. Q. Wu, Z. M. Chen, C. Y. He and X. Zhou, RSC Adv., 2017, 7, 34215.

42 B. Wang, Y. Q. Wu, X. L. Wang, Z. M. Chen and C. Y. He, Sens. Actuators, B, 2014, 190, 157.

43 X. F. Ma, J. Z. Sun, M. Wang, M. Hu, G. Li, H. Z. Chen and J. Huang, Sens. Actuators, B, 2006, 114, 1035.
44 R. G. Parkhomenko, A. S. Sukhikh, D. D. Klyamer, P. O. Krasnov, S. Gromilov, B. Kadem, A. K. Hassan and T. V. Basova, J. Phys. Chem. C, 2017, 121, 1200.

45 Z. Y. Yu, B. Wang, Y. Li, D. Kang, Z. M. Chen and Y. Q. Wu, RSC Adv., 2017, 7, 22599.

46 T. Yanaia, D. P. Tew and N. C. Handyb, Chem. Phys. Lett., 2004, 393, 51.

47 E. D. Glendening, A. E. Carpenter and F. Weinhold, $N B O$, version 3.1, 1995.

48 M. J. Frisch, et al., Gaussian 09, Revision B01, Gaussian, Inc., Wallingford, CT, 2009.

49 P. Li, Y. Ding, A. Wang, L. Zhou, S. H. Wei, Y. M. Zhou, Y. W. Tang, Y. Chen, C. X. Cai and T. H. Lu, ACS Appl. Mater. Interfaces, 2013, 5, 2255.

50 P. Li, H. L. Liu, J. Yang, D. M. Sun, Y. Chen, Y. M. Zhou, C. X. Cai and T. H. Lu, J. Mater. Chem. B, 2013, 179, 32.

51 R. O. Ogbodu, J. L. Limson, E. Prinsloo and T. Nyokong, Synth. Met., 2015, 204, 122.

52 V. Mani, R. Devasenathipathy, S. M. Chen, J. A. Gu and S. T. Huang, Renewable Energy, 2015, 74, 867.

53 K. Hou, L. Huang, Y. B. Qi, C. X. Huang, H. B. Pan and M. Du, Mater. Sci. Eng., C, 2015, 49, 640.

54 L. Song, Z. R. Wei, B. C. Wang, Z. Luo, S. M. Xu, W. K. Zhang, H. X. Yu, M. Li, Z. Huang, J. F. Zang, F. Yi and H. Liu, Chem. Mater., 2016, 28, 1205.

55 C. H. Liu, H. L. Tai, P. Zhang, Z. B. Ye, Y. J. Su and Y. D. Jiang, Sens. Actuators, B, 2017, 246, 85.

56 H. Song, X. Li, P. Cui, S. X. Guo, W. H. Liu and X. L. Wang, Sens. Actuators, B, 2017, 244, 124. 